Institute for Experimental Medical Research

Center for Heart Failure Research

Ullevål University Hospital

University of Oslo

\title{
Molecular Mechanisms in Heart Failure
}

The Role of Syndecan-4 in Development

of Myocardial Hypertrophy and

Heart Failure

Alexandra Vanessa Finsen

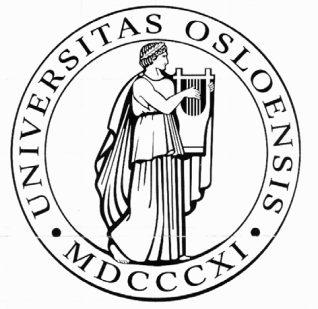

Oslo 2008 


\section{(C) Alexandra Vanessa Finsen, 2008}

Series of dissertations submitted to the

Faculty of Medicine, University of Oslo

No. 640

\section{ISBN 978-82-8072-898-2}

All rights reserved. No part of this publication may be reproduced or transmitted, in any form or by any means, without permission.

Cover: Inger Sandved Anfinsen.

Printed in Norway: AiT e-dit AS, Oslo, 2008.

Produced in co-operation with Unipub AS.

The thesis is produced by Unipub AS merely in connection with the thesis defence. Kindly direct all inquiries regarding the thesis to the copyright holder or the unit which grants the doctorate.

Unipub AS is owned by

The University Foundation for Student Life (SiO) 


\section{Contents}

Acknowledgements 5

$\begin{array}{ll}\text { List of papers } & 6\end{array}$

$\begin{array}{ll}\text { Selected abbreviations } & 7\end{array}$

Introduction $\quad 8$

Congestive heart failure $\quad 8$

$\begin{array}{ll}\text { Definition } & 8\end{array}$

Prevalence $\quad 8$

$\begin{array}{ll}\text { Causes } & 8\end{array}$

$\begin{array}{ll}\text { Early cardiac responses } & 8\end{array}$

Myocardial remodeling $\quad 9$

Induction of myocardial hypertrophy 10

$\begin{array}{ll}\text { Treatment strategies } & 10\end{array}$

Prognosis 11

$\begin{array}{ll}\text { Aims of the study } & 12\end{array}$

Summary of results 13

Paper I 13

Paper II 13

Paper III 13

$\begin{array}{ll}\text { Paper IV } & 14\end{array}$

$\begin{array}{ll}\text { Methodological considerations } & 15\end{array}$

$\begin{array}{ll}\text { Animal models } & 15\end{array}$

$\begin{array}{ll}\text { Echocardiography } & 16\end{array}$

$\begin{array}{ll}\text { Histology and immunohistochemistry } & 16\end{array}$

$\begin{array}{ll}\text { Transmission electron microscopy } & 17\end{array}$

$\begin{array}{ll}\text { Array screening } & 17\end{array}$

$\begin{array}{ll}\text { RT-qPCR } & 17\end{array}$

$\begin{array}{ll}\text { Northern and Western techniques } & 18\end{array}$

$\begin{array}{ll}\text { Measurement of infarct area } & 18\end{array}$

$\begin{array}{lr}\text { Cultured neonatal cardiomyocytes and fibroblasts } & 18\end{array}$

$\begin{array}{ll}\text { Overlay techniques } & 19\end{array}$

$\begin{array}{ll}\text { Pull down techniques } & 19\end{array}$

$\begin{array}{ll}\text { Peptide synthesis and use of blocking peptides } & 20\end{array}$ 
Generation of genetically modified mice $\quad 20$

Measuring $\mathrm{Ca}^{2+}$ ATPase content 20

$\begin{array}{ll}\text { Cardiomyocyte contraction measurements } & 21\end{array}$

$\mathrm{Ca}^{2+}$ imaging $\quad 21$

$\begin{array}{ll}\text { Voltage clamp techniques } & 21\end{array}$

In vivo electrocardiogram recordings $\quad 22$

In vivo isoproterenol infusion $\quad 22$

Discussion $\quad 23$

$\begin{array}{ll}\text { Animal models of human heart disease } & 23\end{array}$

Role of syndecan-4 in pathological hypertrophy and heart failure $\quad 24$

$\begin{array}{ll}\text { Syndecan-4 } & 24\end{array}$

Syndecan-4 expression in CHF 25

Potential mechanisms of action $\quad 25$

Potential direct effect of syndecan- 4 on the regulation of the

$\begin{array}{ll}\text { calcineurin - NFAT pathway } & 27\end{array}$

Syndecan-4 as a new target for therapy 28

Role of SERCA2 in heart failure $\quad 29$

$\begin{array}{ll}\text { Conclusions } & 31\end{array}$

Errata $\quad 32$

Reference List 33 


\section{Acknowledgements}

The work for this thesis was carried out at the Institute for Experimental Medical Research at Ullevål University Hospital. It was made possible by the encouraging and wise guidance by my supervisor Professor Geir Christensen. I am especially grateful for his prompt feedback and relentless interest in the project.

I have appreciated working with skilful colleagues, and want to thank my co-authors Per Reidar Woldbæk, Jian Li, Jiaping Wu, Torstein Lyberg, Theis Tønnessen, Ivar Sjaastad, Even K. Østli, Marianne Lyngra, Hilde O. Jarstadmarken, Cathrine Rein Carlson, Ståle Nygård, Sarah A. Wilcox-Adelman, Paul F. Goetinck, Srdjan Djurovic, Kristin B. Andersson, Yibin Wang, Ju Chen, Kenneth R. Chien, Ole M. Sejersted, Jon Arne K. Birkeland, William E. Louch and Jeffery D. Molkentin for valuable contributions.

I am most grateful to Bjørg Austbø, Unni Lie Henriksen, Annlaug Ødegård, Geir Florholmen, Almira Karahasan, Lisbeth H. Winer, Kristin Arnkværn, Pimthanya W Drågen and Ulla H. Enger for invaluable biochemical assistance. I highly appreciate the technical assistance received from Tævje A. Strømme, Paul F. Gjerpe and Roy Trondsen with illustrations and solving numerous computer problems. I would also like to thank Morten Eriksen, Carsten Lund, Siv Leng Tran, Siv Rong Tran, Ann-Kristin Josefsen and Line Solberg for expert animal care. Furthermore, I would like to acknowledge Ole M. Sejersted, AnneGunn T. Nilsen and Jo-Ann F. Larsen in the administrative staff, for providing good working facilities. I would also especially like to thank each and everyone at the institute for making it a friendly and fun place to work, and not least Elisabeth Leistad for first introducing me to the institute.

The contributions from Tove Noren, Kahsai Beraki and Aud Svindland are also highly appreciated.

Finally, I appreciate the interest family and friends have shown in my work. I am especially grateful to my partner Robin for his encouragement and patience.

Financial support was provided by the Norwegian Research council, Anders Jahres Fund for Promotion of Science, Rakel and Otto Kr. Bruun's Fund and the Ullevål University Hospital Fund. 


\section{List of papers}

The thesis is based on the following papers, which are referred to by their Roman numerals:

I. Alexandra Vanessa Finsen, Per Reidar Woldbak, Jian Li, Jiaping Wu, Torstein Lyberg, Theis Tønnessen, Geir Christensen. Increased syndecan expression following myocardial infarction indicates a role in cardiac remodeling. Physiol Genomics 16: 301-308, 2004.

II. Alexandra Vanessa Finsen, Geir Christensen, Ivar Sjaastad. Echocardiographic parameters discriminating myocardial infarction with pulmonary congestion from myocardial infarction without congestion in the mouse. J Appl Physiol 98: 680 - 689, 2005.

III. Alexandra Vanessa Finsen, Even K. Østli, Marianne Lyngra, Ivar Sjaastad, Hilde O. Jarstadmarken, Ståle Nygård, Sarah A. Wilcox-Adelman, Paul F. Goetinck, Torstein Lyberg, Theis Tønnessen, Srdjan Djurovic, Cathrine R. Carlson, Geir Christensen. Syndecan-4 is essential for activation of the calcineurin-NFAT pathway and development of concentric myocardial hypertrophy.

IV. Kristin B. Andersson, Jon Arne K. Birkeland, Alexandra Vanessa Finsen, William E. Louch, Ivar Sjaastad, Yibin Wang, Ju Chen, Jeffery D. Molkentin, Kenneth R. Chien, Ole M. Sejersted, Geir Christensen. Moderate heart dysfunction in mice with inducible cardiomyocyte-specific deletion of Serca2: A role for SR-independent mechanisms 


\section{Selected abbreviations}

BNP B-type natriuretic peptide

$\mathrm{Ca}^{2+} \quad$ Free calcium ions

CaM Calmodulin

CHF Congestive heart failure

ECM Extra-cellular matrix

FGF-2 Basic fibroblast growth factor

FS Fractional shortening

HGF Hepatocyte growth factor

IL- Interleukin-

LIF Leukemia inhibitory factor

LV Left ventricle

LVEDP Left ventricular end-diastolic pressure

MAPK Mitogen-activated protein kinase

MI Myocardial infarction

$\mathrm{MI}_{\mathrm{nf}} \quad$ Myocardial infarction without congestive failure

$\mathrm{NCX} \quad \mathrm{Na}^{+}-\mathrm{Ca}^{2+}$ exchanger

NFAT Nucleor factor of activated T-cells

PKC Protein kinase C

$\mathrm{PIP}_{2} \quad$ Phospatidylinositol-4,5 biphosphate

PLB Phospholamban

PP Protein phosphatase

RT-qPCR Real time quantitative poly chain reaction

SERCA2 Sarco(endo)plasmatic reticulum $\mathrm{Ca}^{2+}$-ATPase, isoform 2

Sham Animals subjected to operative procedure except ligation of left coraonary artery or banding of aorta

siRNA Silencing RNA

SR Sarcoplasmic reticulum

TNF- $\alpha \quad$ Tumor necrosis factor- $\alpha$

VEGF Vascular endothelial growth factor

VSMC Vascular smooth muscle cells

WT Wild-type 


\section{Introduction}

\section{Congestive heart failure}

\section{Definition}

Congestive heart failure (CHF) can be defined as a syndrome in which the heart is unable to pump sufficient blood to meet the requirements of the peripheral organs in terms of oxygen and cell nutrients at rest and during effort, alternatively only at abnormally elevated diastolic pressures or volumes ${ }^{1}$. This syndrome is normally characterized by the manifestations of intravascular and interstitial volume overload (shortness of breath and edema) and/or signs of inadequate tissue perfusion (fatigue, poor exercise tolerance and renal failure).

\section{Prevalence}

The prevalence of CHF is increasing dramatically throughout the world, despite an overall decline in age adjusted mortality from coronary artery disease (CAD) in developed countries ${ }^{2-}$ 4, 4,5. This trend primarily reflects the strong association between CHF and the rising proportion of elderly people, which have the highest incidence of coronary artery disease and hypertension ${ }^{2}$. There is also a rising prevalence of hypertension, dyslipidemia and diabetes in the industrialized countries. CHF is already the most costly medical illness in the United States $^{6}$, and therefore the possible socioeconomic impact of a future CHF epidemic is truly alarming.

\section{Causes}

The causes of CHF may be impaired myocardial contractility (i.e. systolic contractility), impaired myocardial relaxation or increased ventricular stiffness (i.e. diastolic dysfunction), chronic pressure or volume overload, or other disease states in which the capacity of the heart is exceeded (e.g. anemia, thyrotoxicosis). Any condition causing myocyte death, myocyte dysfunction or ventricular remodeling, or a combination of these, can induce heart failure. In developed countries $\mathrm{CHF}$ is often a long-term outcome of diseases such as CAD, hypertension, valvular disease, myocarditis or idiopathic dilated cardiomyopathy.

\section{Early cardiac responses}

Initially the heart responds with short term adaptive mechanisms consisting of (1) the FrankSterling mechanism, whereby an increased preload helps to sustain cardiac performance; (2) 
activation of neurohumoral systems, including release of norepinephrin which augments myocardial contractility, and activation of the renin-angiotensin-aldosterone system that acts to maintain arterial pressure and perfusion of vital organs; and (3) myocardial remodeling with or without cardiac chamber dilatation, in which myocardial contractile mass is increased ${ }^{7}$.

\section{Myocardial remodeling}

If the initial adaptive mechanisms of the heart are insufficient or the magnitude of the overload increases further, regardless of the initial cause, a relentless deterioration of cardiac structure and function ensues. This so called chronic myocardial remodeling is characterized by myocyte loss due to both necrosis and apoptosis, hypertrophy of individual myocytes, reexpression of fetal genes and changes in quantity and quality of the extra-cellular matrix $(\mathrm{ECM})^{7}$.

In addition to causing myocardial remodeling, hemodynamic stress often causes a decrease in the intrinsic myocyte contractility. There is increasing evidence that disturbances in $\mathrm{Ca}^{2+}$ handling play a central role in the disturbed contractile function observed in heart failure, because $\mathrm{Ca}^{2+}$ has an important role in regulating myocardial contraction and relaxation $^{8-10}$. Myocardium from patients with end-stage heart failure display abnormal prolongation of the action potential and impaired relaxation. These alterations in electrical and contractile properties are associated with a prolonged elevation of the intracellular $\mathrm{Ca}^{2+}$ transient during relaxation. Intracellular $\mathrm{Ca}^{2+}$ transients in failing myocytes demonstrate a blunted rise with depolarization, reflecting slower delivery of $\mathrm{Ca}^{2+}$ to the contractile apparatus, and a slower rate of fall during repolarization. These abnormalities could explain both systolic and diastolic dysfunction.

Myocardial remodeling always comprises changes in mass, volume, shape or composition of the left ventricle, in order to maintain or return systolic stress to normal limits. Left ventricular mass is increased approximately equally in response to both pressure- and volume-overload $^{11}$. There is a substantial increase in wall thickness in pressure-overloaded ventricles, but only a mild or no increase in the volume-overloaded ventricle. In the volumeoverloaded model the increase in wall thickness is only sufficient to counterbalance the increase in left ventricular radius. However, the ratio of wall thickness to radius is substantially increased in pressure-overload. Thus, when the primary stimulus is pressure overload, a parallel replication of myofibrils and thickening of individual myocytes, or so called concentric hypertrophy, is seen. On the other hand, volume overload results in 
increased diastolic wall stress which subsequently causes replication of sarcomeres in series, elongation of myocytes and ventricular dilatation, also called eccentric hypertrophy.

\section{Induction of myocardial hypertrophy}

Hemodynamic overload causes activation of growth factors present in the fetal heart but dormant in the normal adult heart, and these are responsible for stimulating myocyte hypertrophy and regulating the synthesis and degradation of the $\mathrm{ECM}^{7}$. Intracellular signaling pathways that have been implicated in the induction of cardiac hypertrophy include the Gq subunit of heterotrimeric G proteins, the small GTP binding proteins Ras and Rac, the three main branches of the mitogen-activated protein kinase (MAPK) cascades, protein kinase $\mathrm{C}$ (PKC) isoforms and the calcineurin-NFAT pathway. The calcium/calmodulin-dependent protein phosphatase calcineurin is an especially effective inducer of hypertrophy and has been shown to be necessary and sufficient for cardiac growth in response to pathological, but not physiological stimuli ${ }^{12,13}$. Importantly, the calcineurin-NFAT pathway has been shown to interact with both the PKC and MAPK pathways, in order to coordinate the hypertrophic response ${ }^{14,15}$.

Identification of mechanical stress-sensing molecules mediating the extra-cellular stimuli to the appropriate intracellular signalling pathways is one of the most important tasks in cardiovascular biology today. As mechanical stress is normally distributed to cells through the ECM, transduction of the mechanical stimuli may involve molecules that bind the ECM to the cytoskeleton, but exactly which molecules these are is still unknown. The Z-disc proteins have been proposed to be an essential part of the mechanical stretch sensing apparatus in cardiomyocytes ${ }^{16}$. Z-discs are multiprotein complexes with a unique position at the interface of the sarcoplasmic reticulum, cytoskeleton, contractile apparatus and sarcolemma, and play pivotal roles in sarcomeric assembly and organization ${ }^{17}$. The Z-disc proteins are thought not only to function as a physical anchor for myofilament and cytoskeletal proteins, but also as a pivot for reception, transduction and transmission of mechanical and biochemical signals.

\section{Treatment strategies}

The understanding of the underlying pathofysiology and the treatment strategies for heart failure have changed considerably with time. Approximately 50 years ago patients were treated with diuretics, vasodilators and inotropic drugs on the basis of the cardiorenal and cardiocirculatory models of heart failure. Although alleviating edema and improving cardiac hemodynamics and function, this kind of treatment did not succeed in improving long-term 
survival $^{18,19}$. However, with time one realized that the pathophysiological processes involved in $\mathrm{CHF}$ also have effects on cardiovascular reflexes and systemic organ perfusion and function, which in turn stimulate compensatory responses including the renin-angiotensinaldosterone, sympathetic and natriuretic peptide systems ${ }^{20}$. Thus the neurohormonal hypothesis of heart failure was established, and subsequent treatment with angiotensinconverting enzyme inhibitors, aldosterone antogonists and $\beta$-blockers has improved $\mathrm{CHF}$ patients' morbidity and mortality to a certain degree $\mathrm{e}^{21-25}$.

\section{Prognosis}

Despite recent improvements in treatment strategies, CHF still carries a poor prognosis comparable to that of malignant disease ${ }^{26}$. CHF carries a shorter life expectancy for men than women, and its prognosis is worse in elderly subjects of both sexes. Only $35 \%$ of men and $50 \%$ of women are alive 5 years after developing $\mathrm{CHF}^{26-28}$. Mortality rates are also higher in those with low left ventricular ejection fraction and underlying coronary artery disease.

Because of its high prevalence and morbidity, the management of CHF has vast socioeconomic implications. Much still remains to be unraveled with regard to underlying molecular mechanisms in order to develop more effective treatment strategies that will substantially affect morbidity and mortality.

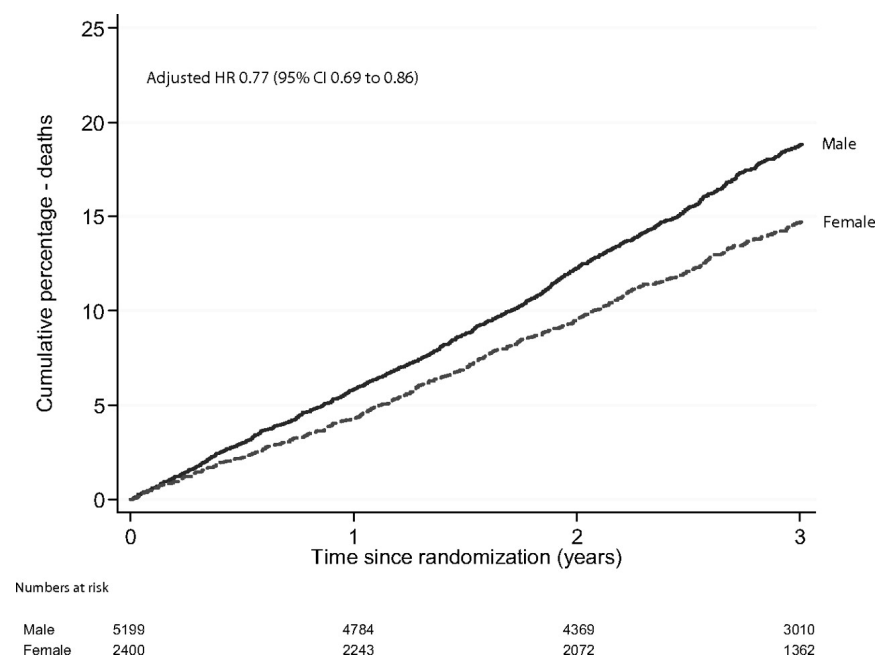

Figure 1. Kaplan-Meier curves for all-cause mortality in CHARM, standardized to median risk and shown by sex. Modified from ${ }^{29}$ and used with permission. 


\begin{abstract}
Aims of the study
The main aim of the thesis was to study underlying molecular mechanisms contributing to development of pathological hypertrophy and heart failure.
\end{abstract}

The specific aims of the separate studies were to:

\title{
Paper I:
}

Identify essential genes with altered expression in the early phase of cardiac remodeling.

Paper II:

Identify parameters describing systolic and diastolic function in mice after MI that reliably discriminate MI with pulmonary congestion from MI without congestion.

Paper III:

To study whether lack of syndecan- 4 affects cardiac structure and function before and after induction of concentric hypertrophy and to study the interaction between syndecan-4 and intracellular signaling cascades.

Paper IV:

To explore the cardiac responses to loss of SERCA2 protein in the postnatal mammalian heart. 


\section{Summary of results}

\section{Paper I:}

cDNA filter array screening was performed on noninfarcted LV tissue from mice subjected to MI and compared to sham-operated mice. As many as $43 \%$ of upregulated genes, and $80 \%$ of induced genes could be related to the ECM. BMP-1, which is known to process procollagen into mature collagen and probiglycan into biglycan, demonstrated increased expression. Furthermore, we identified a subset of interacting genes with increased expression following MI, including syndecan1-4, Wilms tumor protein 1, fibronectin, collagen 6A and fibroblast growth factor receptor 1 .

\section{Paper II:}

Mice subjected to ligation of the left coronary artery were characterized by means of echocardiography and LV catheterization in order to establish non-invasive parameters that reliably discriminate between MI-mice with and without CHF. We found that left atrial diameter and an infarct $>40 \%$ of total LV circumference measured in two-dimensional long axis distinguished MI-mice with and without $\mathrm{CHF}$ on both an average and an individual basis. Mean maximum rate of rise of LV pressure, LV fractional shortening (LVFS), posterior wall shortening velocity and mitral flow deceleration velocity distinguished MI-mice with CHF from those without on a general basis. LV end diastolic pressure (LVEDP) and maximum rate of decline in LV pressure were only able to distinguish mice with CHF from Sham on an average basis.

\section{Paper III:}

Cardiac structure and function of syndecan $-4^{-/-}$mice were characterized before and after induction of concentric hypertrophy. Histology and immunohistochemistry showed normal deposition of collagen, but slightly decreased cellular cohesivity in syndecan- $4^{-/-}$mice. Transmission electron microscopy revealed a $31 \%$ increase in the number of mitochondria and irregular widening of the Z-discs in syndecan $-4^{-/-}$mice. However, syndecan $-4^{-/-}$mice had normal cardiac function at physiological conditions. Following banding of the ascending aorta, syndecan $-4^{-/-}$mice showed no development of concentric hypertrophy, and a significantly lower expression of the hypertrophic marker $\alpha$-skeletal actin as compared to WT. There was also a specific inhibition of the calcineurin-NFAT pathway in syndecan $-4^{-/-}$mice 
during pressure overload. Moreover, syndecan-4 was found to associate with the catalytic subunit of calcineurin (calcineurin A). The binding domain of calcineurin A was mapped to the V-region of syndecan-4, and the syndecan-4 binding domain to the autoinhibitory domain in calcineurin A. Finally, a cell permeable syndecan-4 derived peptide was able to inhibit the calcineurin-NFAT pathway and increase the phosphorylation level of NFAT.

\section{Paper IV:}

A genetically modified mouse allowing time-specific Serca2 deletion in cardiomyocytes induced by tamoxifen was generated. Four weeks after tamoxifen injection, SERCA2a protein level was $<5 \%$ of control in the myocardium and undetectable in cardiomyocytes.

Surprisingly, cardiac function was largely preserved at this time (cardiac output $80 \%$ of controls), and no myocardial hypertrophy was observed. Importantly, the $\mathrm{Ca}^{2+}$ influx through the L-type $\mathrm{Ca}^{2+}$ channel and extrusion of $\mathrm{Ca}^{2+}$ through the sodium calcium exchanger, as well as myafilament responsiveness were both enhanced, maintaining cardiac contractility. 


\section{Methodological considerations}

\section{Animal models}

Using mice as experimental animals has several benefits in that they are small, cheap, well characterized and possible to modify genetically. On the other hand there are many different strains of mice which vary to a certain degree with regard to anatomy and physiology, and mice can be both in-bred and out-bred. In Paper I we used Balb-C mice which are albino. The use of albino animals in experiments has been criticized especially when used in neuropsychiatric research, because of the animals' reduced hearing and eyesight. However, these aberrations would not seem as important in studies of cardiac function. Apart from Balb-C, only C57-Black 6 mice and genetically modified animals on a C57-Black 6 background were used. Both strains are in-bred, reducing the genetic variability to a minimum. C57-Black-6 mice do have increased susceptibility for developing atherosclerosis though, which could potentially influence cardiac function. This does however only start to manifest itself at a much more advanced age than what was examined in these studies.

The animals were anesthetized with propofol and isoflurane in order to minimize cardiac depression. Any kind of anesthesia will affect cardiac function to a certain degree, leaving the conditions under which the examination is carried out somewhat un-physiological. However, by standardizing and optimizing the anetehesia as much as possible, one is at least able to look at relative differences between groups.

The primary operations consisting of ligation of the left coronary artery and banding of the ascending aorta, are described in detail in Paper III and elsewhere ${ }^{30}$. Since both involve rather large operations, it is obviously always necessary to compare the responses in these to sham-operated animals, in order to be able to exclude the effects of the operation itself. Banding of the aorta is achieved rather quickly compared to the natural development of an aortic stenosis, which the procedure is intended to imitate, while ligation of the left coronary artery is more comparable to an acute infarction with regard to time-course. However, it may be argued that the pathogenesis is not analogue to that of atherosclerotic coronary disease and MI in humans, given that the mice have healthy coronary arteries. Nevertheless, the coronary artery ligation and aortic banding models have been shown to be valid models for investigating post-infarction myocardial remodeling and concentric myocardial hypertrophy, respectively ${ }^{31}$.

The secondary operations performed in this thesis are also described elsewhere ${ }^{32,33}$, and these often included left ventricular catheterization. During this procedure a $1.4 \mathrm{~F}$ catheter 
was used to measure hemodynamic parameters. Due to the small proportions in mice, even a catheter of this delicate size occludes a substantial part of the aorta, thus increasing afterload acutely. However, since we used the same method in all groups of animals examined, we believe that the observed differences reflect the relative in vivo differences.

\section{Echocardiography}

Echocardiography is a non-invasive method that can give serial and detailed information about in vivo cardiac function. The method is described in detail in Paper II.

Echocardiography is widely used in humans, but only recently in mice. In mice the high heart rate and short working distance represent a technical challenge. We used a fully digital system with modified software that allowed sufficient time resolution for reliable end-systolic and diastolic measurements. A 13-MHz linear array transducer designed for the examination of small rodents was also used, giving a sufficiently short working distance.

As echocardiography is both examiner- and interpreter-dependent, echocardiographic measurements were analyzed by two persons blinded for the intervention carried out, to assess interscorer reliability. Intrascorer reliability was also assessed.

\section{Measurement of infarct area}

In addition to measuring infarct size echocardiographically in Paper II, infarct area was measured after excision of the heart. The endocardium was unfolded and photographed with a digital camera. Total endocardial area and infarcted area were then traced, and infarct size as percentage of total area was calculated using Image $\mathrm{J} 1.32 \mathrm{j}$ software. The free-hand tracing of the different areas represented a challenge with regard to exactness, but on the other hand the demarcation between infarcted and non-infarcted areas was relatively easy to identify. Our results showed good correlation with echocardiographic findings, indicating reliability of both methods.

\section{Histology and immunohistochemistry}

When interpreting histological and immunohistolgical sections one has to take into account that these methods are only semiquatitative, and interpreter-dependent. Cutting sections as thin as $5 \mu \mathrm{m}$ is fraught with pitfalls, including folding of the sections, tearing of thin structures and making lines and distortions due to uneven or blunt knifes. The methods used for fixation, staining and antibody incubation, can all distort the morphology and organization of the tissue examined to a certain degree. Staining of sections can be uneven. Finally, the 
antibodies used for immunohistochemistry can be of varying quality with regard to specificity and avidity. Our samples were interpreted by two experienced pathologists who were blinded for genotype and intervention.

\section{Transmission electron microscopy}

Obtaining correct and comparable fiber orientation is essential when performing transmission electron microscopy on cardiac tissue. Considering the minute dimensions, slicing of sections is a considerable challenge. The correct interpretation of findings is dependent on considerable experience and knowledge within the field. In our case two experienced electron microscopists interpreted the findings.

\section{Array screening}

The cDNA filter array strategy provides an efficient means of simultaneously analyzing a large number of RNA transcripts and is most helpful as a hypothesis generating tool. Apart from ensuring optimal technical conditions, it is imperative to make sufficient repeated comparisons when performing the screening. Furthermore, it is essential to have stringent criteria for defining genes as differentially expressed in order to be able to make deductions. Last but not least, it is necessary to confirm the findings by other means like PCR or Northern blotting. In Paper I where we used array screening, we were able to confirm all up-regulated genes tested, by means of Northern blotting.

\section{RT-qPCR}

Real-time RT-qPCR has emerged as the method of choice for gene expression analyses, and as it is highly sensitive, represents a convenient method especially when the amount of RNA is limited. As for all methods that require isolation of RNA it is very important to avoid degradation of the material by immediate snap freezing, as well as avoiding repeated freezing and thawing cycles. Treatment of the material with DNase is necessary in order to avoid DNA giving false signals in the assay. Likewise, varying quality of the RNA obtained can result in false differences in observed amount of PCR product. In our experiments the RNA quality was evaluated using bioanalyzer (Agilent) producing a RIN value (RNA Integrity Number). In order for the RT-PCR method to be quantitative, it is essential to use exact same input of total RNA for each sample when performing the reversed transcription into cDNA, otherwise the efficiency of cDNA synthesis has to be verified using a standard curve. It is also necessary to know that the efficiency of the RT-PCR reaction is constant at different concentrations. The 
accumulation of PCR-product was monitored for each cycle using fluorescent probes (TaqMan), assuring that data were collected in the exponential phase of the amplification, which is necessary for high reproducibility as well as for obtaining quantitative results. The specificity of the primers and probes used is naturally also of great importance. In our experiments we used primers and probes with high specificity, and for comparisons of results obtained from different 96 well plates we made sure to normalize against an endogenous control (RpL4), which was run on the same plate at the same time. RpL4 is previously shown not to be regulated in heart failure.

\section{Northern and Western techniques}

As mentioned above, all steps must be taken to avoid degradation of the material before isolation of either mRNA or protein. When measuring degree of phosphorylation of different proteins by means of Western blots, prolonged storage of the material should be avoided as this can cause dephosphorylation in itself. Moreover, using antibodies and probes with highest possible specificity increases the chances of obtaining correct results. When several samples from different groups are compared using Western, it is very important to perform a loading control, for example by staining the membranes with Coomassie blue, in order to be able to correct for uneven loading on the gel, or transmittance of protein to the membrane. In the cases where the samples are so many that they have to be run on two different gels, it is essential to have common samples on both gels enabling normalization between the two.

\section{Cultured neonatal cardiomyocytes}

Neonatal ventricular cardiomyocytes from mice were isolated as described by Masahiko Hoshijima, University of California, San Diego, USA, and the method is described in some detail in Paper III. The cardiomyocyte cell cultures were found to have a purity of $92 \%$ as determined by staining of nuclei and F-actin. 


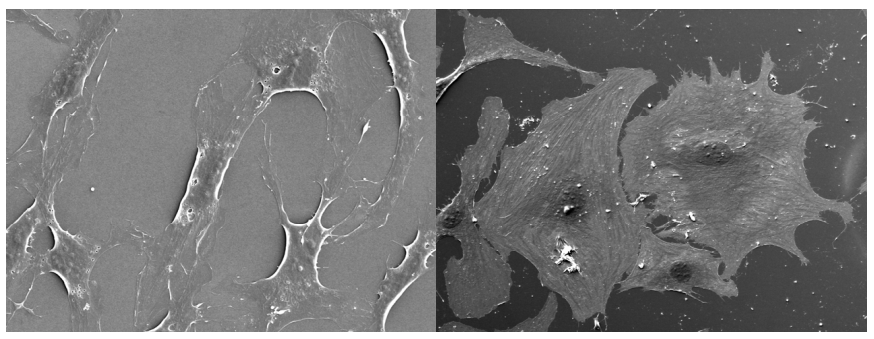

Figure 2. Neonatal cardiac fibroblasts and cardiomyocytes. Electron micrograph of cultured neonatal fibroblasts (left panel) showing their typical spindle-shape and faintly visible nuclei, and of cardiomyocytes (right panel) showing more rounded cells with prominent nuclei and abundant fibrillar cytosolic structures.

Neonatal cardiomyocytes are the most commonly used cells for in vitro studies of cardiomyocytes, mainly because they are easier to culture and have the potential to grow. Adult cardiomyocytes are larger, grow more slowly in vitro and have a limited potential for differentiation. In vivo the cardiomyocytes subjected to pathological stimuli are terminally differentiated, and therefore one could argue that adult cardiomyocytes are a more accurate model. However, both types of cells react to hypertrophic stimuli with characteristic changes in gene expression. So although the model has some limitations, neonatal cardiomyocytes represent a useful tool for studying the effects of potential pathological stimuli, like different cytokines or electrical pacing, in vitro.

With regard to species, rat cardiomyocytes are substantially easier to isolate and culture, compared to murine. However, the study of cardiomyocytes from genetically modified animals necessitates the use of murine cells.

\section{Overlay techniques}

Overlay is a useful method for detecting binding between proteins in vitro. As peptide sequences are synthesized on membranes, the method only allows for detection of linear bindings, not bindings requiring a certain tertiary conformation or oligomerization. Another weakness of the method is false positive results resulting from overloading of the membranes, giving non-specific binding.

\section{Pull down techniques}

This is another in vitro method for detecting binding between proteins. Contrary to overlays, this technique allows for oligomerization of the proteins, as peptide sequences are bound to 
beads instead of membranes. Therefore, pull down experiments are potentially able to detect more protein-protein interaction than overlays.

\section{Peptide synthesis and use of blocking peptides}

Peptides have previously been shown to become cell-permeable by coupling eleven arginine recidues to the $\mathrm{N}$ terminus ${ }^{34}$, enabling blockage of intracellular molecule interactions. However, dose and time needed for maximum effect may wary widely from peptide to peptide, and between different types of cells. In Paper III these aspects were not studied specifically, and chosen dose and incubation time was based on a previous study where Tcells were incubated with a high-affinity PKA binding peptide ${ }^{35}$. Therefore, there is no guarantee that we achieved maximum degree of blockage, but at least differences between groups were detected. It is not possible to exclude that the arginine residues added to the peptide have effects in their own right. For this reason scrambled peptides containing the same arginine residues were used as controls. Finally, it is possible that intentionally blocking one interaction might lead to novel interactions and effects, not occurring in untreated cells. If so, one would end up studying the effects of resulting new interactions, rather than the intended inhibition of an interaction. However, having found increased levels of pNFAT both in syndecan $-4^{-/-}$mice subjected to AB and in WT cardiomyocytes treated with blocking peptides, we feel decreases the likelihood of this in our case.

\section{Generation of genetically modified mice}

It is outside the scope of this thesis to discuss the technical details and considerations that are important in generating genetically modified mice. However, this is reviewed by Williams et $\mathrm{al}^{36}$. One general consideration worth mentioning, is the importance of the genetic background on which the genetic modification is carried out, as the same mutation can cause different phenotypes in mice with different genetic backgrounds. In other words it is imperative to have considerable knowledge about the genetic background of the mice used for genetic modification, to ensure that they do not have undesirable traits with regard to the focus of interest. It is also important to compare these animals to wild-type animals of the same background.

\section{Measuring $\mathrm{Ca}^{2+}$ ATPase content}

The assay used in Paper IV for measuring $\mathrm{Ca}^{2+}$ ATPase content in homogenates measures all covalently bound ATP. The homogenates were therefore lysated with lye to exclude the 
contribution of the Na-K ATPase, and identify the contribution of SERCA2. It is worth mentioning that this procedure does not exclude the contribution of the PMCA, but that its contribution is considered to be minor. Finally, the severely reduced content of $\mathrm{Ca}^{2+}$ ATPase measured in the SERCA2 KO animals, would be expected to challenge the assay's ability to distinguish the real $\mathrm{Ca}^{2+}$ ATPase content from background, rendering these results somewhat inexact. However, this gives no reason to question that the content of $\mathrm{Ca}^{2+}$ ATPase found in the SERCA2 KO animals was severely reduced.

\section{Cardiomyocyte contraction measurements}

Cardiomyocyte contraction measurements were performed with the method described in Paper IV, using a video camera coupled with a video edge detector. The cells contracted isotonically without external resistance against movement during these measurements. The conditions did therefore not completely resemble the in vivo situation where there is a combination of isometric and isotonic contraction. However, unloaded cell shortening measurements are widely used as a valid measure of cell contractile function ${ }^{37}$.

\section{$\mathrm{Ca}^{2+}$ imaging}

In Paper IV calcium transients were detected by confocal fluorescence imaging. The contribution of sarcoplasmic reticulum (SR) function to the size of the $\mathrm{Ca}^{2+}$ transient was calculated as the decrease in $\mathrm{Ca}^{2+}$ transient magnitude upon application of caffeine (the caffeine-sensitive component of the transient), and the $\mathrm{SR} \mathrm{Ca}^{2+}$ content was estimated by the magnitude of the caffeine-induced transient. It is worth mentioning however, that these calculations do not take into account the possibility that the cells contain other caffeine sensitive compartments.

\section{Voltage clamp technique}

The voltage clamp technique was used to measure $\mathrm{L}$-type $\mathrm{Ca}^{2+}$ and $\mathrm{Na}^{+}-\mathrm{Ca}^{2+}$-exchanger (NCX) currents in Paper IV, where the method is described in some detail. Pipettes were introduced into the cardiomyocytes, the membrane potential was tightly controlled and the currents from the ionic channels were identified by use of drugs and manipulation of the superfusing solutions. A SR $\mathrm{Ca}^{2+}$ loading procedure was always performed first. And since this in itself affects the amount of $\mathrm{Ca}^{2+}$ loaded into SR, and therefore the currents released, this procedure was standardized as much as possible. Patch electrodes (pipettes) with 3-5 M $\Omega$ 
resistance were used. This gives fast voltage control, but on the other hand dialysis of cell constituents out of the cell, which can influence excitation-contraction coupling.

A discontinuous voltage clamp technique was used, in which an amplifier switches between injecting the current needed to reach the test-potential and measuring the actual membrane potential at the tip of the pipette. This method allows accurate control of membrane potential and enables measurements of rise time and actual voltage off-line. This method is however slower than the continuous clamp technique.

\section{In vivo electrocardiogram recordings}

Electrocardiogram recording were carried out on mice for measurement of the Q-T interval in Paper IV. During the procedure the animals were only lightly anesthetized with $2 \%$ isoflurane via a mask in order to achieve as close to physiological conditions as possible. In addition, rate-corrected Q-T values were calculated to minimize the effect of a potential difference in heart rate response in the two genotypes

Another challenge was to minimize the noise on the recordings, enabling exact determination of the Q-T interval. Satisfactory quality was achieved by replacing the electrodes, shaving the animal for optimal contact between animal and electrode, the use of earthing and turning off all nearby electrical apparatus. In addition, the average of 10 consecutive complexes was calculated, also in order to account for variation due to respiration.

\section{In vivo isoproterenol infusion}

Isoproterenol infusion via the left femoral vein was carried out in Paper IV in order to examine the cardiac response to $\beta$-adrenergic stimulation. Isoproterenol is a very potent drug and the doses given were miniscule, necessitating the use of a highly accurate micro-infusion pump. Intravascular localization of the catheter was confirmed by aspiration of blood into the catheter. As these experiments would last up to 90 minutes, it was obviously very important to control and maintain a physiological body temperature, and minimize fluid loss from the animal. Furthermore, anesthetic agents had to be carefully chosen in order to achieve minimal cardiac depression and avoid blunting of the $\beta$-adrenergic response. Isoflurane is known to blunt the $\beta$-adrenergic response, and therefore we had to choose other agents for these experiments. 


\section{Discussion}

\section{Animal-models of human heart disease}

The amount and type of cardiac research that can be performed on humans is for obvious reasons limited, especially with regard to studies on myocardial tissue. Therefore one has had to resort to animals. The species used to create CHF depends on ethical and economic considerations, accessibility and reproducibility of the model, as well as the scientific question studied. The model should mimic the clinical setting of heart failure as closely as possible in order to study pathophysiological processes, while this may be less important when a defined causal connection is under investigation. There is no ideal animal model that both perfectly imitates human heart failure and is technically feasible in the laboratory. Many protocols have a sudden onset of heart failure, whereas human heart failure will usually develop over years. In humans heart failure is often associated with atherosclerosis, obesity, diabetes or hypertension, while this is usually not present in the animal models. Furthermore, most models use young adult animals, whereas heart failure in humans frequently is a disease of the elderly. Finally, one must not forget that simple variations in animal handling and housing procedures, such as cage density, diet, strain, gender, as well as site, timing and type of anesthesia used during operative procedures have been shown to profoundly affect biochemical, hematological and endocrine/metabolic parameters ${ }^{38}$.

Previously, a large number of studies were performed in animals with overt clinical heart failure, and this yielded a lot of information on hemodynamics, neurohormonal activation, myocardial function and molecular alterations in the failing heart ${ }^{39}$. However, with recent invasive and non-invasive technologies hemodynamics can be studied in patients. Furthermore, cardiac transplantation surgery has made end-stage failing human myocardium available for functional, biochemical and molecular biology studies. On the other hand, it is still rather difficult to study myocardial changes during compensated heart failure, the transition from hypertrophy to failure and during the process of remodeling. For this purpose animal models are still critically important.

Traditionally the pig has been avidly used in heart research, as it is said to have the heart most comparable to humans. However, the pig is not very well suited for genetic modification, mainly because the whole genome is still not sequenced, but also because it is relatively expensive to keep, has a long gestation period and produces few offspring. Mice on the other hand, have a completely mapped genome, are cheap and easily bred into large numbers, and also have strong developmental, physiological and biochemical similarities with 
humans. Ninety-nine percent of the mouse genome is homolog to the human genome. For these reasons, and also because of the flexibility by which informative mutations can be generated in almost any mouse gene, the mouse has quickly become the most used model in biomedical research. A major disadvantage with the mouse in relation to cardiac research however, is its small size. This represents a challenge when doing hemodynamic measurements, and also with regard to the small amounts of material obtainable for further analysis.

Advances in transgene and gene targeting technology have provided important insight into the molecular mechanisms underlying cardiac physiology and pathophysiology. Murine models have been engineered harboring gene mutations leading to phenotypes reminiscent of human clinical disease states including congenital heart defects, cardiomyopathies and cardiac conduction defects (for an overview see Refs. ${ }^{40-42}$ ). In order to understand the relationship between genes, proteins and functional alterations, and to establish models in which the pathogenic processes can be studied longitudinally, it is necessary to direct the heart to delete or synthesize the candidate protein stably, in the absence of other pleiotrophic changes. One can then determine whether or not the protein's presence causes an effect directly or indirectly. Techniques allowing gene manipulation in a spatial- and temporal-specific manner enable loss of the gene of interest wherever and whenever desired with targeted DNA recombination via the cre-loxP system, further increasing the precision of the genetic manipulation. Lack of target specificity can complicate or even confound the ability to dissect out the direct effect of the gene on cardiac function, especially if the target gene is critical to the function of other organ systems. In respect to transgenesis, development of systems allowing the transgene expression to be turned on and then shut off again during an animal's life-span, is warranted. This would offer the researchers a chance not only to observe whether a particular transgene can cause disease, but also whether the heart is able to recover when the transgene is turned off.

\section{Role of syndecan-4 in pathological hypertrophy and heart failure}

\section{Syndecan-4}

The syndecans consists of a family of four transmembrane heparan sulphate proteoglycans important in cell-ECM binding ${ }^{43}$. Syndecan-4 is the only member found in cardiomyocytes ${ }^{44}$, and has been localized to costameres ${ }^{45}$, focal adhesions ${ }^{46}$ and Z-discs ${ }^{45}$, all of which are 
thought to be important sites of signal transduction ${ }^{47-49}$. Moreover, syndecan-4 is a coreceptor for several growth factors and integrins ${ }^{50}$.

\section{Syndecan-4 expression in CHF}

Several factors have been shown to regulate syndecan-4 expression. However, syndecan-4 expression during concentric hypertrophy and CHF has so far not been examined, even though there are a few studies that have looked at syndecan- 4 expression in the cardiovascular system. Others have shown that intramyocardial adenoviral PR39, a prolin/arginine-rich peptide, injections in a pig model of chronic myocardial ischemia increased syndecan-4 expression, and improved the perfusion and function of ischemic myocardium, at least partly through angiogenesis ${ }^{51,52}$. Shi et al. found that $\alpha_{1}$-adrenergic receptor activation increased the expression of syndecan-4 in cell adhesion functional assays, indicating a role for syndecan-4 in regulating cell morphology, remodeling and signaling ${ }^{53}$. Furthermore, Zhang et al. were able to show that TNF- $\alpha$ secreted by hypoxic myocytes was able to induce syndecan- 4 expression in human endothelial cells ${ }^{54}$. It has also been established that syndecan-4 expression is rapidly induced in cultured vascular smooth muscle cells (VSMCs) in response to basic fibroblast growth factor (FGF-2) or serum stimulation, identifying syndecan-4 as a primary response gene product in $\mathrm{VSMCs}^{55}$. In addition, different types of injury, like skin wounds ${ }^{51}$, vascular wall injury ${ }^{55}$ and myocardial infarction ${ }^{44,56}$ have been shown to increase syndecan-4 expression. And finally, Li and co-workers were able to show that subjecting adventitial fibroblast to a mechanical stretch protocol produced a rapid increase in syndecan-4 expression that was accompanied by both enhanced protein shedding and disassembly of focal adhesions, indicating that mechanical strain tightly regulates syndecan-4 expression ${ }^{56}$.

\section{Potential mechanisms of action}

Despite many potentially important functions, the role of syndecan- 4 in development of pathological hypertrophy and heart failure has not to our knowledge been studied before. We have shown (Paper III) that lack of syndecan-4 inhibits development of concentric hypertrophy following pressure overload, strongly indicating that syndecan-4 does indeed have an important role. 


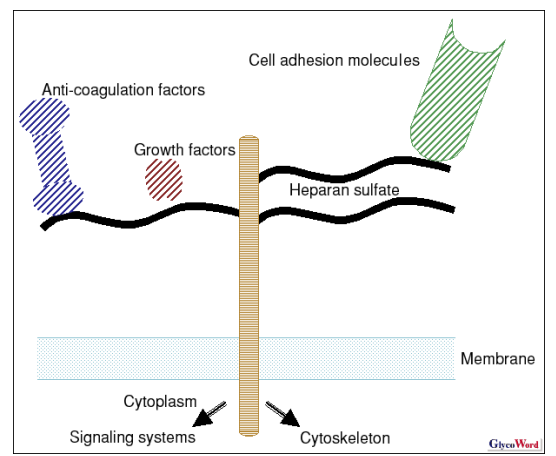

Figure 3. Functions of syndecan-4. Schematic illustration of the diverse functions of syndecan-4, both extraand intra-cellularly. Used with permission.

The function as co-receptor for growth factors like FGF-2 ${ }^{57}$, vascular endothelial growth factor $(\mathrm{VEGF})^{58}$ and hepatocyte growth factor $(\mathrm{HGF})^{59}$ could potentially be important in this setting. FGF-2 is known to be essential for the manifestation of overload- and angiotensin-induced cardiac hypertrophy ${ }^{60,61}$, and likewise, FGF-2 released by paced cardiomyocytes was found necessary for the hypertrophic response. The endothelial cell mitogen VEGF has an essential role in vasculogenesis and angiogenesis ${ }^{62}$. VEGF blockade has been found to result in reduced myocardial capillary density, accelerated contractile dysfunction and pathological cardiac remodeling ${ }^{63}$. The pluripotent growth factor HGF has potent angiogenic and anti-apoptotic functions ${ }^{64,65}$. In accordance with this, blocking endogenous HGF worsened cardiac failure and increased mortality in a rat model of ischemic injury ${ }^{66}$, while HGF gene transfer following a large MI resulted in significantly preserved myocardial function and geometry, was associated with significant angiogenesis and a reduction in apoptosis ${ }^{67}$.

The cytoplasmic domain of syndecan-4 has been shown to regulate various intracellular signaling pathways. Previous studies have shown that syndecan-4 binds to and regulates the localization, activity and stability of PKC- $\alpha$ in other cell-types ${ }^{68}$, which itself has been shown to regulate cardiac contractility and propensity towards heart failure ${ }^{69}$. Our study demonstrated that lack of syndecan-4 specifically inhibited the pro-hypertrophic calcineurinNFAT pathway during pressure overload in mice, and that it inhibited development of concentric hypertrophy. This is a previously unknown and potentially very important effect of syndecan-4, as there is considerable evidence that the calcineurin-NFAT pathway plays an important role in development of pathological, but not physiological, hypertrophy ${ }^{70-72}$. 


\section{Potential effect of syndecan-4 on the regulation of the calcineurin-NFAT pathway}

Twenty-four hours after aortic banding syndecan $-4^{-/-}$mice showed significantly higher levels of pNFATc4 and decreased activity of calcineurin, strongly indicating decreased activity of this pathway. We postulated that syndecan-4 binds and activates calcineurin. This hypothesis was based on our findings, together with the knowledge that syndecan-4 is known to bind and activate PKC- $\alpha$ and that PKC- $\alpha$ activity is increased upon activation of the calcineurin-NFAT pathway ${ }^{14}$. The unique ability of syndecan- 4 to activate PKC- $\alpha$ in the absence of $\mathrm{Ca}^{2+}$ was first demonstrated by $\mathrm{Oh}$ et al., who also showed a requirement for phosphatidylinositolo-4,5biphosphate $\left(\mathrm{PIP}_{2}\right)^{73}$.Activation of PKC- $\alpha$ depends on the phosporylation status of Ser179 in the cytoplasmic domain of syndecan-4, because phosphorylation of Ser179 decreases the affinity for $\mathrm{PIP}_{2}$. Interestingly, Ser179 is dephosphorylated by an as yet unknown serine phosphatase $^{74}$, which could potentially be calcineurin. Furthermore, phosphorylation of Ser179 has been shown to cause a conformational change near the $\mathrm{C} 2$ region of syndecan- 4 that ablates an interaction site with the PDZ domain of several proteins ${ }^{75}$. The PDZ domain of CASK can bind to the $\mathrm{C} 2$ region of syndecans, and coincidently binds the known calcineurin activator calmodulin ${ }^{76}$. Therefore we hypothesized that a direct interaction between calcineurin and syndecan-4 results in dephosphorylation of Ser179 causing the conformational change in $\mathrm{C} 2$ needed for the binding of CASK and calmodulin, ultimately leading to the activation of calcineurin by bringing calcineurin and calmodulin in close proximity.

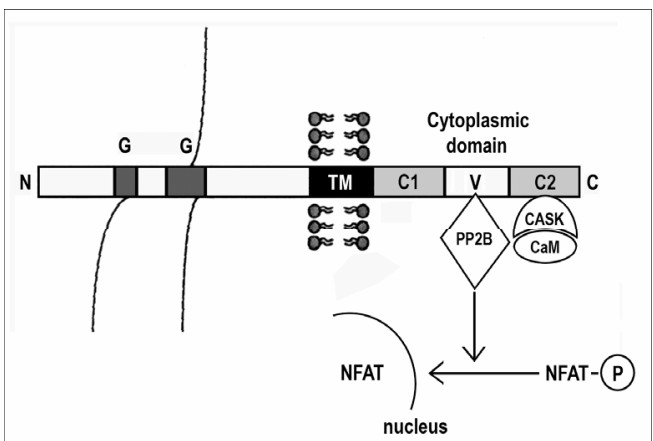

Figure 4. Hypothesized interaction between syndecan-4 and calcineurin/PP2B. Calcineurin dephosphorylates Ser179 in the V region of syndecan-4, allowing CASK and calmodulin (CaM) to bind to the $\mathrm{C} 2$ region of syndecan-4, thereby facilitating the activation of calcineurin by bringing calcineurin and CaM in close proximity. 
In accordance with our hypothesis we were able to show an association between syndecan-4 and calcineurin, by means of pull-down experiments. Furthermore we mapped the calcineurin A binding domain to the V-region of syndecan-4, and the syndecan-4 binding domain to the autoinhibitory domain in calcineurin A. Finally, we created a cell-permeable syndecan-4 derived peptide which was able to inhibit the calcineurin-NFAT pathway and increase the phosphorylation level of NFAT. Upon pull-down experiments calmodulin was not pulled down with the syndecan-4 peptides, contradicting a direct interaction between the two, and further supporting our hypothesis.

\section{Syndecan-4 as a new target for therapy}

Our results indicate benefits from inhibiting the actions of syndecan-4 at some point during pressure overload. We found that inhibiting development of concentric hypertrophy from the beginning was detrimental to cardiac function. However, halting the development of further pathological hypertrophy could be beneficial at a later time-point, implying the benefits of time-specific inhibition of syndecan- 4 .

A sophisticated way of achieving time-specific inhibition of syndecan-4 in the future could hypothetically be the use of siRNA technology. This gene silencing technology is based on the use of sequence-specific short interfering RNA which have been found to form an RNA-induced silencing complex with other cellular proteins, resulting in selective degradation of the complementary single-stranded target RNA in a sequence specific manner. In vivo delivery of siRNA can either be carried out locally or systematically. Systemic delivery would have the disadvantage of affecting syndecan- 4 gene expression in all cells, while local administration to the myocardium could for obvious reasons represent a challenge.

In general, it would seem optimal to endeavor an organ-specific inhibition, in addition to time specificity, in order to avoid the possible side effects of inhibiting the actions of syndecan-4 in all cells. For instance lack of syndecan- 4 has been shown to decrease the rate of wound healing ${ }^{77}$ and increase mortality following lipopolysaccharide induced sepsis ${ }^{78}$.

With regard to inhibiting the fore mentioned known and postulated intracellular functions of syndecan-4, a major challenge would be to develop a therapeutic strategy able to access the cytoplasmic tail of syndecan-4. The use of a peptide disruptor represents a future possibility in this respect. This technology is based on development of peptides able to penetrate cells and bind to the binding sequence of interest with higher affinity than any other ligand, resulting in delineation of the mediated intracellular signalling ${ }^{35}$. In our case, 
disruption of the calcineurin binding motif on syndecan-4 should inhibit the calcineurinNFAT pathway and be cardioprotective.

\section{Role of SERCA2 in heart failure}

Muscle contraction is initiated when $\mathrm{Ca}^{2+}$ enters the cell via the L-Type $\mathrm{Ca}^{2+}$ channels in the sarcolemma and triggers the release of large amounts of $\mathrm{Ca}^{2+}$ from the SR via the ryanodine receptor ${ }^{79,80}$. The concentration of cytosolic $\mathrm{Ca}^{2+}$ determines the extent of muscle activation and thus force generation. SERCA pumps $\mathrm{Ca}^{2+}$ back into the SR and is therefore responsible for muscle relaxation and replenishing $\mathrm{Ca}^{2+}$ stores needed for the next contraction ${ }^{81}$. SERCA activity is regulated by PLB, which in its unphosphorylated state lowers the affinity of SERCA for $\mathrm{Ca}^{2+82} \cdot \mathrm{Ca}^{2+}$ removal by the NCX in the sarcolemma also contributes to maintenance of intracellular $\mathrm{Ca}^{2+}$ homeostasis ${ }^{83}$.

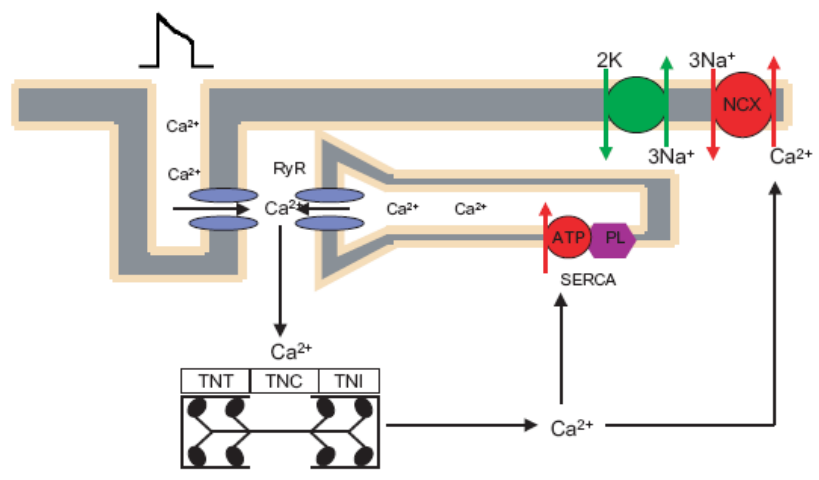

Figure 5. Schematic representation of $\mathrm{Ca}^{2+}$ homeostasis in cardiomyocytes. RyR, ryanodin receptor; TNT, troponin T; TNC, troponin C; TNI, troponin I; ATP reflects energy consumption of SERCA; PL, phospholamban; NCX, sodium-calcium exchanger; SERCA, Sarco(endo)plasmatic reticulum $\mathrm{Ca}^{2+}$ ATPase. Modified from ${ }^{8}$ and used with permission.

Abnormalities commonly seen in CHF include a negative force-frequency relationship associated with disturbed $\mathrm{Ca}^{2+}$ handling ${ }^{84,85}$ characterized by increased diastolic $\mathrm{Ca}^{2+}$ content, reduced $\mathrm{SR} \mathrm{Ca}^{2+}$ content and increased duration and reduced amplitude of $\mathrm{Ca}^{2+}$ transients.

Several studies suggest that down-regulation of SERCA activity underlies these abnormalities, possibly in combination with increased NCX activity. A promising approach to restoring functional abnormalities found in CHF could therefore be adenoviral gene therapy to compensate for decreased SERCA synthesis. 
Transgenic animals with increased SERCA levels in the heart have demonstrated that increases in SERCA pump levels alter $\mathrm{Ca}^{2+}$ homeostasis and enhance contractile function in the heart ${ }^{86-88}$. Heterozygous mice with one functional allele after disruption of the SERCA2 gene by homologous recombination on the other hand, showed a $\sim 35 \%$ reduction in SERCA2a protein levels and maximal velocity of $\mathrm{SR} \mathrm{Ca}^{2+}$ uptake $^{89}$. Despite not developing cardiac hypertrophy or heart failure, these heterozygous mice did display moderate cardiac dysfunction on in vivo measurements, as well as a more than $30 \%$ decreased peak amplitude of $\mathrm{Ca}^{2+}$ transients in isolated myocytes, resulting in decreased rates of cell shortening and relengthening.

In our mice with cardiac specific deletion of the Serca2 gene described in Paper IV, function was to our surprise largely preserved after four weeks, despite them having $<5 \%$ SERCA2 protein in the myocardium compared to the mice with no deletion. Although deletion of the SERCA2 gene in adult mice ultimately caused myocardial dysfunction, our study shows that cardiac function is well preserved for several weeks despite loss of SERCA2 protein. The L-type $\mathrm{Ca}^{2+}$ channel current, the NCX current and the sarcolemmal $\mathrm{Ca}^{2+}$ ATPase protein were increased and may contribute to the enhanced non-SR dependent maintenance of $\mathrm{Ca}^{2+}$ transients. Thus, $\mathrm{Ca}^{2+}$ influx and efflux across the plasma membrane may represent a powerful mechanism for cardiomyocyte contraction that compensates for loss of SR function. Our data also indicate that the myofilament $\mathrm{Ca}^{2+}$ responsiveness is increased to compensate for the small $\mathrm{Ca}^{2+}$ transients. Taken together, our findings show that the mouse heart is able to deal with an extreme reduction in SERCA2 protein before any development of overt heart failure occurs. 


\section{Conclusions}

\section{Paper I:}

There is an up-regulation of a large number of ECM-associated genes in the non-infarcted region following MI in the mouse. The observed up-regulation of BMP-1 may have a particularly important role in this context, since it processes procollagen into collagen and activates latent growth factors. Moreover, considering the ability of syndecan-4 to bind the cytoskeleton to the ECM and its role as a required receptor for FGF, the observed increase in syndecan-4 on both RNA and protein level, suggests a role in cardiac remodeling following MI.

\section{Paper II:}

Significantly increased left atrial diameter and infarct size $>40 \%$ of total LV circumference may serve as major criteria for heart failure with congestion after MI in mice.

\section{Paper III:}

Lack of syndecan-4 inhibits both development of concentric hypertrophy and activation of the calcineurin-NFAT pathway in response to chronic pressure overload. Furthermore, the calcineurin A binding domain is located in the V-region of syndecan-4 and the syndecan-4 binding domain in the autoinhibitory domain in calcineurin A. Finally, a cell permeable syndecan-4 derived peptide inhibits the calcineurin-NFAT pathway and increase the phosphorylation level of NFAT.

\section{Paper IV:}

In adult mice with a cardiomyocyte-specific deletion of the Serca2 gene, enhanced $\mathrm{Ca}^{2+}$ cycling over the plasma membrane together with increased myofilament responsiveness represent powerful compensatory mechanisms that largely preserve in vivo cardiac function. 


\section{Errata}

\section{Paper III}

Page 2, line 7-8: the following part of the sentence should be deleted; "and calmodulin, a known calcineurin activator"

\section{Paper IV}

Page 9, line 14: the correct denomination for cell capacitance is $\mathrm{pF}$.

Page 9, line 21- page 10, line 1: reduction in peak myocardial contraction velocity was $38 \%$, and reduction in peak relaxation velocity was $28 \%$

Page 1 in Supporting Information, line 13, 16, 19 and 20: the correct denomination for isoproterenol dose is $\mathrm{ng} / \mathrm{min} / \mathrm{kg}$. 


\section{Reference List}

1. Braunwald,E. \& Bristow,M.R. Congestive heart failure: fifty years of progress. Circulation 102, IV14-IV23 (2000).

2. Kelly,D.T. Disease burden of cardiovascular disease in the elderly. Coron. Artery Dis. 8, 667-669 (1997).

3. Goldberg,R.J., Glatfelter,K., Burbank-Schmidt,E., Lessard,D., \& Gore,J.M. Trends in community mortality due to coronary heart disease. Am. Heart J. 151, 501-507 (2006).

4. Lampe,F.C. et al. Is the prevalence of coronary heart disease falling in British men? Heart 86, 499-505 (2001).

5. Stewart,S., MacIntyre,K., Capewell,S., \& McMurray,J.J. Heart failure and the aging population: an increasing burden in the 21 st century? Heart 89, 49-53 (2003).

6. O'Connell,J.B. \& Bristow,M.R. Economic impact of heart failure in the United States: time for a different approach. J. Heart Lung Transpl.. 13, S107-S1 12 (1994).

7. Colucci,W.S. \& Braunwald,E. Pathophysiology of heart failure. eds.

Braunwald, E., Zipes, D. P., \& Libby, P. Heart disease. [6th edition], 503-528. 2001. Philadelphia, Pennsylvania, W.B. Saunders Company.

Ref Type: Serial (Book,Monograph)

8. Hasenfuss, G. \& Pieske,B. Calcium cycling in congestive heart failure. J. Mol. Cell Cardiol. 34, 951-969 (2002).

9. Piacentino,V., III et al. Cellular basis of abnormal calcium transients of failing human ventricular myocytes. Circ. Res. 92, 651-658 (2003).

10. Del,M.F. \& Hajjar,R.J. Targeting calcium cycling proteins in heart failure through gene transfer. J. Physiol 546, 49-61 (2003).

11. Grossman,W., Jones,D., \& McLaurin,L.P. Wall stress and patterns of hypertrophy in the human left ventricle. J. Clin. Invest 56, 56-64 (1975).

12. Molkentin,J.D. et al. A calcineurin-dependent transcriptional pathway for cardiac hypertrophy. Cell 93, 215-228 (1998).

13. Wilkins,B.J. et al. Calcineurin/NFAT coupling participates in pathological, but not physiological, cardiac hypertrophy. Circ. Res. 94, 110-118 (2004).

14. De Windt,L.J., Lim,H.W., Haq,S., Force,T., \& Molkentin,J.D. Calcineurin promotes protein kinase $\mathrm{C}$ and c-Jun NH2-terminal kinase activation in the heart Cross-talk between cardiac hypertrophic signaling pathways. J. Biol. Chem. 275, 13571-13579 (2000).

15. Sanna,B., Bueno,O.F., Dai,Y.S., Wilkins,B.J., \& Molkentin,J.D. Direct and indirect interactions between calcineurin-NFAT and MEK1-extracellular signal- 
regulated kinase $1 / 2$ signaling pathways regulate cardiac gene expression and cellular growth. Mol. Cell. Biol. 25, 865-878 (2005).

16. Knoll,R. et al. The cardiac mechanical stretch sensor machinery involves a Z disc complex that is defective in a subset of human dilated cardiomyopathy. Cell 111, 943-955 (2002).

17. Clark,K.A., McElhinny,A.S., Beckerle,M.C., \& Gregorio,C.C. Striated muscle cytoarchitecture: an intricate web of form and function. Annu. Rev. Cell Dev. Biol. 18, 637-706 (2002).

18. Cohn,J.N. et al. Effect of vasodilator therapy on mortality in chronic congestive heart failure. Results of a Veterans Administration Cooperative Study. $N$. Engl. J. Med. 314, 1547-1552 (1986).

19. Packer,M. et al. Effect of oral milrinone on mortality in severe chronic heart failure. The PROMISE Study Research Group. N. Engl. J. Med. 325, 1468-1475 (1991).

20. Anker,S.D. \& Rauchhaus,M. Heart failure as a metabolic problem. Eur. J. Heart Fail. 1, 127-131 (1999).

21. Effects of enalapril on mortality in severe congestive heart failure. Results of the Cooperative North Scandinavian Enalapril Survival Study (CONSENSUS). The CONSENSUS Trial Study Group. N. Engl. J. Med. 316, 1429-1435 (1987).

22. Pitt,B. et al. The effect of spironolactone on morbidity and mortality in patients with severe heart failure. Randomized Aldactone Evaluation Study Investigators. $N$. Engl. J. Med. 341, 709-717 (1999).

23. Effect of metoprolol CR/XL in chronic heart failure: Metoprolol CR/XL Randomised Intervention Trial in Congestive Heart Failure (MERIT-HF). Lancet 353, 2001-2007 (1999).

24. The Cardiac Insufficiency Bisoprolol Study II (CIBIS-II): a randomised trial. Lancet 353, 9-13 (1999).

25. Packer,M. et al. The effect of carvedilol on morbidity and mortality in patients with chronic heart failure. U.S. Carvedilol Heart Failure Study Group. N. Engl. J. Med. 334, 1349-1355 (1996).

26. Ho,K.K., Anderson,K.M., Kannel,W.B., Grossman,W., \& Levy,D. Survival after the onset of congestive heart failure in Framingham Heart Study subjects.

Circulation 88, 107-115 (1993).

27. Cleland,J.G., Gemmell,I., Khand,A., \& Boddy,A. Is the prognosis of heart failure improving? Eur. J. Heart Fail. 1, 229-241 (1999).

28. MacIntyre,K. et al. Evidence of improving prognosis in heart failure: trends in case fatality in 66547 patients hospitalized between 1986 and 1995. Circulation 102, 1126-1131 (2000). 
29. O'Meara,E. et al. Sex differences in clinical characteristics and prognosis in a broad spectrum of patients with heart failure: results of the Candesartan in Heart failure: Assessment of Reduction in Mortality and morbidity (CHARM) program. Circulation 115, 3111-3120 (2007).

30. Iversen,P.O., Woldbaek,P.R., Tonnessen,T., \& Christensen,G. Decreased hematopoiesis in bone marrow of mice with congestive heart failure. Am. J. Physiol Regul. Integr. Comp Physiol 282, R166-R172 (2002).

31. Christensen,G., Wang,Y., \& Chien,K.R. Physiological assessment of complex cardiac phenotypes in genetically engineered mice. [Review] [106 refs]. Am. J. Physiol. 272, H2513-H2524 (1997).

32. Finsen,A.V., Christensen,G., \& Sjaastad,I. Echocardiographic parameters discriminating myocardial infarction with pulmonary congestion from myocardial infarction without congestion in the mouse. J. Appl. Physiol. 98, 680-689 (2005).

33. Finsen,A.V. et al. Increased syndecan expression following myocardial infarction indicates a role in cardiac remodeling. Physiol. Genomics 16, 301-308 (2004).

34. Futaki,S. Membrane-permeable arginine-rich peptides and the translocation mechanisms. Adv. Drug Del. Rev. 57, 547-558 (2005).

35. Carlson,C.R. et al. Delineation of type I protein kinase a selective signaling events using an ri anchoring disruptor (RIAD). J. Biol. Chem.(2006).

36. Williams,R.S. \& Wagner,P.D. Transgenic animals in integrative biology: approaches and interpretations of outcome. J. Appl. Physiol 88, 1119-1126 (2000).

37. Delbridge,L.M. \& Roos,K.P. Optical methods to evaluate the contractile function of unloaded isolated cardiac myocytes. J. Mol. Cell Cardiol. 29, 11-25 (1997).

38. Champy,M.F. et al. Mouse functional genomics requires standardization of mouse handling and housing conditions. Mamm. Genome 15, 768-783 (2004).

39. Hasenfuss, G. Animal models of human cardiovascular disease, heart failure and hypertrophy. Cardiovasc. Res. 39, 60-76 (1998).

40. Dalloz,F., Osinska,H., \& Robbins,J. Manipulating the contractile apparatus: genetically defined animal models of cardiovascular disease. J. Mol. Cell Cardiol. 33, 9-25 (2001).

41. Christensen,G., Wang,Y., \& Chien,K.R. Physiological assessment of complex cardiac phenotypes in genetically engineered mice. Am. J. Physiol 272, H2513H2524 (1997).

42. Berul,C.I. Electrophysiological phenotyping in genetically engineered mice. Physiol. Genomics 13, 207-216 (2003). 
43. Bernfield,M. et al. Functions of cell surface heparan sulfate proteoglycans. Annu. Rev. Biochem. 68, 729-777 (1999).

44. Li,J., Brown,L.F., Laham,R.J., Volk,R., \& Simons,M. Macrophage-dependent regulation of syndecan gene expression. Circ. Res. 81, 785-796 (1997).

45. VanWinkle,W.B. et al. Localization of the transmembrane proteoglycan syndecan-4 and its regulatory kinases in costameres of rat cardiomyocytes: A deconvolution microscopic study. Anat. Rec. 268, 38-46 (2002).

46. Woods,A. \& Couchman,J.R. Syndecan 4 heparan sulfate proteoglycan is a selectively enriched and widespread focal adhesion component. Mol. Biol. Cell 5, 183-192 (1994).

47. Sharp,W.W., Simpson,D.G., Borg,T.K., Samarel,A.M., \& Terracio,L. Mechanical forces regulate focal adhesion and costamere assembly in cardiac myocytes. Am. J. Physiol 273, H546-H556 (1997).

48. Romer,L.H., Birukov,K.G., \& Garcia,J.G. Focal adhesions: paradigm for a signaling nexus. Circ. Res. 98, 606-616 (2006).

49. Pyle,W.G. \& Solaro,R.J. At the crossroads of myocardial signaling: the role of Z-discs in intracellular signaling and cardiac function. Circ. Res. 94, 296-305 (2004).

50. Tkachenko,E., Rhodes,J.M., \& Simons,M. Syndecans - New kids on the signaling block. Circ. Res. 96, 488-500 (2005).

51. Gallo,R.L. et al. Syndecans, Cell-Surface Heparan-Sulfate Proteoglycans, Are Induced by A Proline-Rich Antimicrobial Peptide from Wounds. Proc. Natl. Acad. Sci. U. S. A. 91, 11035-11039 (1994).

52. Post,M.J. et al. Adenoviral PR39 improves blood flow and myocardial function in a pig model of chronic myocardial ischemia by enhancing collateral formation. Am. J. Physiol Regul. Integr. Comp Physiol 290, R494-R500 (2006).

53. Shi,T. et al. Novel \{alpha\}1-Adrenergic Receptor Signaling Pathways: Secreted Factors and Interactions with the Extracellular Matrix. Mol. Pharmacol.(2006).

54. Zhang,Y., Pasparakis,M., Kollias,G., \& Simons,M. Myocyte-dependent regulation of endothelial cell syndecan-4 expression. Role of TNF-alpha. J. Biol. Chem. 274, 14786-14790 (1999).

55. Cizmeci-Smith,G., Langan,E., Youkey,J., Showalter,L.J., \& Carey,D.J. Syndecan-4 is a primary-response gene induced by basic fibroblast growth factor and arterial injury in vascular smooth muscle cells. Arterioscler. Thromb. Vasc. Biol. 17, 172-180 (1997).

56. Li,L. et al. Regulation of syndecan-4 expression with mechanical stress during the development of angioplasty-induced intimal thickening. J. Vasc. Surg. 36, 361370 (2002). 
57. Volk,R., Schwartz,J.J., Li,J., Rosenberg,R.D., \& Simons,M. The role of syndecan cytoplasmic domain in basic fibroblast growth factor-dependent signal transduction. J. Biol. Chem. 274, 24417-24424 (1999).

58. Zhang,Y.F., Li,J.Y., Partovian,C., Sellke,F.W., \& Simons,M. Syndecan-4 modulates basic fibroblast growth factor 2 signaling in vivo. Am. J. Physiol. Heart Circ. Physio. 284, H2078-H2082 (2003).

59. Cornelison,D.D., Filla,M.S., Stanley,H.M., Rapraeger,A.C., \& Olwin,B.B. Syndecan-3 and syndecan-4 specifically mark skeletal muscle satellite cells and are implicated in satellite cell maintenance and muscle regeneration. Dev. Biol. 239, 7994 (2001).

60. Schultz,J.E. et al. Fibroblast growth factor-2 mediates pressure-induced hypertrophic response. J. Clin. Invest. 104, $709-719$ (1999).

61. Pellieux,C. et al. Dilated cardiomyopathy and impaired cardiac hypertrophic response to angiotensin II in mice lacking FGF-2. J. Clin. Invest 108, 1843-1851 (2001).

62. Shiojima,I. \& Walsh,K. Role of Akt signaling in vascular homeostasis and angiogenesis. Circ. Res. 90, 1243-1250 (2002).

63. Izumiya,Y. et al. Vascular endothelial growth factor blockade promotes the transition from compensatory cardiac hypertrophy to failure in response to pressure overload. Hypertension 47, 887-893 (2006).

64. Bussolino,F. et al. Hepatocyte growth factor is a potent angiogenic factor which stimulates endothelial cell motility and growth. J. Cell Biol. 119, 629-641 (1992).

65. Matsumoto,K. \& Nakamura,T. Emerging multipotent aspects of hepatocyte growth factor. J. Biochem. (Tokyo) 119, 591-600 (1996).

66. Nakamura,T. et al. Myocardial protection from ischemia/reperfusion injury by endogenous and exogenous HGF. J. Clin. Invest 106, 1511-1519 (2000).

67. Jayasankar,V. et al. Gene transfer of hepatocyte growth factor attenuates postinfarction heart failure. Circulation 108 Suppl 1, II230-II236 (2003).

68. Keum,E. et al. Syndecan-4 regulates localization, activity and stability of protein kinase C-alpha. Biochem. J. 378, 1007-1014 (2004).

69. Braz,J.C. et al. PKC-alpha regulates cardiac contractility and propensity toward heart failure. Nat. Med. 10, 248-254 (2004).

70. Bueno,O.F., van,R.E., Molkentin,J.D., Doevendans,P.A., \& De Windt,L.J. Calcineurin and hypertrophic heart disease: novel insights and remaining questions. Cardiovasc. Res. 53, 806-821 (2002).

71. Wilkins,B.J. \& Molkentin,J.D. Calcium-calcineurin signaling in the regulation of cardiac hypertrophy. Biochem. Biophys. Res. Commun. 322, 1178-1191 (2004). 
72. Molkentin,J.D. Calcineurin-NFAT signaling regulates the cardiac hypertrophic response in coordination with the MAPKs. Cardiovasc. Res. 63, 467-475 (2004).

73. Oh,E.S., Woods,A., \& Couchman,J.R. Syndecan-4 proteoglycan regulates the distribution and activity of protein kinase C. J. Biol. Chem. 272, 8133-8136 (1997).

74. Horowitz,A. \& Simons,M. Regulation of syndecan-4 phosphorylation in vivo. J. Biol. Chem. 273, 10914-10918 (1998).

75. Koo,B.K. et al. Structural basis of syndecan-4 phosphorylation as a molecular switch to regulate signaling. J. Mol. Biol. 355, 651-663 (2006).

76. Cohen,A.R. et al. Human CASK/LIN-2 binds syndecan-2 and protein 4.1 and localizes to the basolateral membrane of epithelial cells. J. Cell Biol. 142, 129-138 (1998).

77. Echtermeyer,F. et al. Delayed wound repair and impaired angiogenesis in mice lacking syndecan-4. J. Clin. Invest. 107, R9-R14 (2001).

78. Ishiguro,K. et al. Syndecan-4 deficiency leads to high mortality of lipopolysaccharide-injected mice. J. Biol. Chem. 276, 47483-47488 (2001).

79. Bers,D.M. \& Perez-Reyes,E. Ca channels in cardiac myocytes: structure and function in Ca influx and intracellular Ca release. Cardiovasc. Res. 42, 339-360 (1999).

80. Fabiato,A. Calcium-induced release of calcium from the cardiac sarcoplasmic reticulum. Am. J. Physiol 245, C1-14 (1983).

81. MacLennan,D.H. Purification and properties of an adenosine triphosphatase from sarcoplasmic reticulum. J. Biol. Chem. 245, 4508-4518 (1970).

82. Simmerman,H.K. \& Jones,L.R. Phospholamban: protein structure, mechanism of action, and role in cardiac function. Physiol Rev. 78, 921-947 (1998).

83. Hryshko,L.V. \& Philipson,K.D. Sodium-calcium exchange: recent advances. Basic Res. Cardiol. 92 Suppl 1, 45-51 (1997).

84. Lindner,M., Erdmann,E., \& Beuckelmann,D.J. Calcium content of the sarcoplasmic reticulum in isolated ventricular myocytes from patients with terminal heart failure. J. Mol. Cell Cardiol. 30, 743-749 (1998).

85. Mercadier,J.J. et al. Altered sarcoplasmic reticulum Ca2(+)-ATPase gene expression in the human ventricle during end-stage heart failure. J. Clin. Invest $\mathbf{8 5}$, 305-309 (1990).

86. He,H. et al. Overexpression of the rat sarcoplasmic reticulum Ca2+ ATPase gene in the heart of transgenic mice accelerates calcium transients and cardiac relaxation. J. Clin. Invest 100, 380-389 (1997). 
87. Baker,D.L. et al. Targeted overexpression of the sarcoplasmic reticulum Ca2+ATPase increases cardiac contractility in transgenic mouse hearts. Circ. Res. 83, 1205-1214 (1998).

88. Muller,O.J. et al. Transgenic rat hearts overexpressing SERCA2a show improved contractility under baseline conditions and pressure overload. Cardiovasc. Res. 59, 380-389 (2003).

89. Periasamy,M. \& Huke,S. SERCA pump level is a critical determinant of $\mathrm{Ca}(2+)$ homeostasis and cardiac contractility. J. Mol. Cell Cardiol. 33, 1053-1063 (2001). 
